\title{
Demythologising Gender in Development: Feminist Studies in African Contexts
}

\section{Amina Mama}

\section{Introduction}

Feminism - an international political and intellectual movement to challenge the subordination of women - has many roots and trajectories. The theoretical and practical aspects of this movement draw connections between the local and the global manifestations of women's ongoing subordination, across the various movements that seek to advance liberation and development, and across the various academic disciplines that organise social theory.

The impact of feminism on the global development industry has led to many things, only some of which are as radical and progressive as their instigators dreamed. The interaction between feminism and development has generated a series of approaches to development, a need for gender expertise - something of a travelling circus of experts - gender technocrats touting a new kind of export product, whose brand-name has shifted with the decades, from Women in Development (WID) to Women and Development (WAD) to Gender and Development (GAD) to gender mainstreaming. These new women (and some gender-expert men) service the industry, but their value to the alleged beneficiaries of development remains debatable, as conditions of ordinary women and men in the former colonies of the West continue to worsen.

Developmental feminism can be understood as a product of the liaison between feminism and the development industry, and can be traced back to the initiation of the global development interest in women, and was early manifest in the UN Decade of the 1970s and 1980s. ${ }^{1}$ If one were to take a long view, one might be tempted to draw an analysis that examines developmental feminism, tracing it back to precursors in feminist internationalism and the idea of global sisterhood. These were roundly challenged for their ethnocentrism when women from Africa, Asia, Latin America and the Caribbean joined North American and European women on the international stages of the UN Decade for Women (1975-85).

Nationally-based expressions of feminism took various forms, some radical, some liberal. Both state feminism and development feminism are organised around a liberal politics of entryism, i.e. getting women into existing institutions and into development, rather than transforming these. Both display very pragmatic tendencies that have taken on new import in the era of neo-liberalism. Whatever trajectory one traces, it is clear that developmental feminism has been the result of at times quite complex negotiations that reflect the rapid growth and proliferation of feminist thought and strategy on the one hand, and the long arm of much more powerful players in the development industry on the other. The unequal power and authority has ensured a dynamic of appropriation and incorporation that constantly subverts and depletes transformative feminist agendas. The only evidence I have for this assertion is the fact that in real terms, women at the post-colonial periphery have seen their prospects deteriorate further with each new development era. A few years ago I noted that:

The United Nations response to international feminism might have been a case of radical politics being incorporated and neutralised, but it nonetheless signalled the growing currency of feminist concerns within the global arena ... this created ... institutional needs for WID expertise, which in turn generated a bureaucratic discourse on women in development. The fact that this bureaucratic discourse developed largely within the practical exigencies of conducting rapid appraisals and developing politics and project proposals meant that it was often far 
removed from the liberatory concerns of the international women's movement ... (Mama 1997: 417)

African feminists have been consistently critical of the manner in which African nation-states jumped onto the WID bandwagon in ways that in the end failed to advance more radical and liberatory feminist agendas.

Today, now that the state has been rolled back, and in some instances collapsed entirely, one might want to speak less of bureaucratisation and more of marketisation. The poorly defined and even more poorly understood logic of "market forces" has largely supplanted the hegemony, and some might say the protection of, the state. That this shift has been accompanied by financial stringencies that thwart and subvert social justice agendas whenever these do not "add value" in the immediate term, only makes it harder to live with. Basically, it produces a levelling down instead of a levelling up of the various public and educational services that a tax-paying public might reasonably expect not to have to pay for.

Within the world of global development feminism has made complicated inroads, the product of complex negotiations within and across the hierarchies of power that drive the development industry. Each apparent advance has generated its own challenges and risks; each manoeuvre has been greeted with new manoeuvres. As we enter the "knowledge society", a key concern must be the global inequalities played out in the arena of knowledge production, in which I include feminist knowledge production.

\section{Women's studies, gender studies, feminist studies}

Apart from the various structures, policies and projects that have resulted from WID, WAD and GAD approaches to development (Jackson and Pearson 1998), feminism has also generated a large and diverse body of theoretical and conceptual tools, a corpus of methodologies and approaches to knowledge-building, an impressive array of pedagogical innovations and adaptations that are deployed by teachers, a substantial body of new knowledge, and an internationalisation of women's studies.

Mohanty (2003: 518-23) describes three types of Western feminist interest in the non-Western world: the feminist-as-tourist/international consumer, the feminist-as-explorer who is more open-minded but no less voracious a consumer and finally, the feminist solidarity/comparative feminist studies type. All three are US-based, and while we might recognise the "types" and even encounter them all quite frequently, I am more concerned to address the epistemological and practical challenges that face feminist scholars living and working in the rest of the world. I will draw on the African contexts with which I am most familiar.

It is worth recalling that one of the major contributions of feminist epistemology, enriched as it has been by the interventions of Southernbased feminists, is an insistence on being constantly alert to the politics of location and diversities of class, race, culture, sexuality and so on. Feminist epistemology also seeks to build understanding of the connections between the local and global, between the micropolitics of subjectivity and everyday life, and the macropolitics of global political economy. This reflects a commitment to a certain holism, to challenging and subverting the disciplinary and locational fragmentations which have tended to demarcate and circumscribe the theorising of gender and gender relations.

Feminist theorists therefore straddle many intellectual and institutional arenas, in which they face the challenge of keeping global and local levels of analysis in their sights. They must therefore cultivate the navigational skills required to move between the different - and at times competing levels of analysis and to network effectively.

In the academic arena, whether one refers to women's studies, gender studies or feminist studies, it is clear that feminist thought has generated a great deal of intellectual ferment across all the disciplines. Feminist studies have often been deeply subversive, overturning pre-existing assumptions, pre-existing histories of knowledge, and transforming preexisting accounts of human history with rich and interesting "herstories" that function to complete and to subvert the masculine-dominated canons that went before.

However, the myth that feminism has only generated good and radical things needs to be constantly debunked. There are also less than radical gender interventions, in which gender is applied as a depoliticised, technical device, leading perhaps to more statistical data on women, gender analysis denuded so that it ceases to challenge the patriarchal 
power of the development industry, and instead "adds value" to existing meta-narratives.

It is my intention to explore some of the ways in which the changes in development brought about by local and global feminist interventions have played out in African contexts, with particular reference to the potential of gender and women's studies units as a site for feminist activism. I will then outline some of the strategic implications that arise from this exploration, and end by outlining some of the ways in which African scholars working in gender and women's studies are responding to present challenges. ${ }^{2}$

\section{African contexts}

Africa has for centuries occupied a special place in human mythology, a dark and antithetical land of fables and fantasies to those among the early Europeans who gave it a thought. The advent of modern science did little to interrupt this fabulous status, but rather continued to construct the continent as a series of myths that grew more gothic with every generation, as underdevelopment gained ground. The thing about myths is that they contain kernels of truth, but assume a power far beyond that kernel, and the mythologisation of Africa has indeed had devastating effects. However, feminism has emerged in its own right in many African contexts and can be traced back to the eighteenth and nineteenth centuries if not earlier, as early manuscripts from Egypt and Southern Africa demonstrate.

Throughout the late twentieth century and into the twenty-first, the connections between feminist activism and feminist scholarship in African contexts have been complicated by a broad context which includes the dominance of developmentalism, something that does not feature so much in Western histories of feminism, perhaps because only a minority of Western feminists have found a place in the development industry. In practical terms, the availability of even limited resources for women's projects has generated a plethora of organisations, networks and movements, most of which are yet to be documented with any seriousness. ${ }^{3}$

Continental feminist scholarship has a key role to play in the demythologisation of Africa, and of African women and gender relations in particular. To what extent does it fulfil this role, and counter the generalisations of global development industry and its appending of gender? To what extent is it developing into a critical and independent field of work, linking theory and practice, networking across institutions and fields, and unleashing the critical capacities offered by the vantage point: African, gendered female?

In the African context, gender and women's studies has been a growth area over the last two decades. From just a handful of centres in the early 1990s, the field has grown to include 30 or more sites, spread over Africa's 316 universities. ${ }^{4}$ The oldest of these are those at the Women's Documentation Centre in the Institute of African Studies at the University of Ibadan and the Women's Documentation Centre at the University of Dar Es Salaam, while the largest is the Department of Women and Gender Studies at Makerere University. The greatest concentrations are found in the countries with the most universities, notably Nigeria and South Africa. ${ }^{5}$

The intellectual content of the teaching varies, but even a cursory survey indicates that the vast majority of these teach in the area of development. Very few teach, or admit to teaching in more controversial fields, such as sexuality or genderbased violence, and those that do place it under the respectable rubric of health or population studies, rather than treating it as a key aspect of gender, or even gender and development. This suggests a degree of pragmatism, and a willingness to comply with often conservative administrative rationales. ${ }^{6}$ Yet it is already clear that theorising both sexuality and the pervasiveness of violence are key development issues in countries ravaged by conflict and the HIV/AIDS pandemic.

The African Gender Institute has foregrounded an agenda of delivering intellectually rigorous teaching and research in gender studies rooted in the particular challenges posed by various African contexts, and inspired by the emergent community of feminist scholar-activists working to produce socially conscious intellectuals skilled in critical feminist analysis, theory-building, research and pedagogical skills. What this has meant in practice is a focus on teaching, research and writing as political praxis, in pursuit of equality and justice in African contexts.

However, those engaged in teaching point to a number of constraints. Institutional challenges arise from overextension and underfunding, while intellectual challenges arise from the limited availability of locally generated research and publications required to sustain regional intellectual agendas. ${ }^{7}$ Yet the existing 
programmes and departments now provide gender and/or women's studies to thousands of young Africans eager to contribute to regional development and transformation towards more just and equitable societies.

\section{Conclusions}

Gender and Women's Studies has emerged through the nexus between feminism and development, and this has been responsible for as many constraints as opportunities, as can be seen from the myths

\section{Notes}

1. UN feminism elaborated elsewhere (Mama 1997: 416-17).

2. This section draws on the African Gender Institute's current programme to strengthen gender and women's studies in African contexts.

3. While there are usually token contributions from Africa in the global collections on women's movements, which are usually given rather short thrift in the commentaries, there are still very few comprehensive studies and very few of these have been produced by African scholars in their own right (e.g. Tripp and Kwesiga 2002).

\section{References}

African Gender Institute (AGI), 2002, 'Strengthening gender and women's studies in African contexts', workshop report, January, Cape Town, South Africa, www.gwsafrica.org/ workshops/main 2 .html, accessed 5 July 2004

Jackson, C. and Pearson, R., 1998, Feminist Visions of Development, London: Routledge

Mama, A., 1997, 'Afterword', in A. Imam, A. Mama and F. Sow, Engendering African Social Sciences, and fables currently circulating under the variously named rubrics of women in development, women and development, gender in development, gender and development and even feminist visions of development. Feminist intellectual capacities have a key role to play in developing the capacity to think beyond the myths and fables, and work towards a more liberatory feminist praxis.

Critical gender studies - feminist studies - has a crucial role to play in the realisation of more just and equitable development agendas.

4. There are currently over 800 degree-awarding departments and programmes in gender and women's studies in the USA.

5. Details available at www.gwsafrica.org.

6. The situation is similar to that within government, with regard to the establishment of the national machinery for women all over Africa, as an export product. No-one assumes a single structure can or should address women's issues in Western contexts.

7. See African Gender Institute (AGI) (2002) 'Strengthening Gender and Women's Studies in African Contexts', workshop report available at www.gwsafrica.org.

Dakar: Council for the Development of Social Science Research in Africa (CODESRIA)

Mohanty, C., 2003, "Under Western eyes" revisited: feminist solidarity through anticapitalist struggles', Signs: Journal of Women in Culture and Society, Vol 28 No 2

Tripp, A.M. and Kwesiga, J., 2002, The Women's Movement in Uganda: History, Challenges and Prospects, Kampala: Fountain Publishers 